\title{
Population dynamics of exotic rugose spiralling whitefly, Aleurodicus rugioperculatus Martin (Hemiptera: Aleyrodidae) on coconut as influenced by weather factors and natural enemies
}

\author{
K. Elango* and S. Jeyarajan Nelson \\ Department of Agricultural Entomology, Centre for Plant Protection Studies, Tamil Nadu Agricultural University, \\ Coimbatore-641 003, Tamil Nadu, India
}

(Manuscript Received: 18-03-2020, Revised: 06-07-2020, Accepted: 10-07-2020)

\begin{abstract}
The rugose spiralling whitefly, Aleurodicus rugioperculatus Martin is a new exotic pest occurring in several crops including coconut since 2016 in India. Due to variation in the agro-climatic conditions of different regions, arthropods show varying trends in their incidence also in nature and extent of damage to the crop. Besides, abiotic factors also play a key role in determining the incidence and dominance of a particular pest and their natural enemies in a crop ecosystem. The population dynamics of new exotic whitefly species, A. rugioperculatus and their associated natural enemies was assessed on five-year-old Chowghat Orange Dwarf coconut trees at Coconut Farm of Tamil Nadu Agricultural University. The study indicated that RSW was found throughout the year on coconut and the observation recorded on weekly interval basis shows that $A$. rugioperculatus population escalated from the first week of July 2018 (130.8 nymph leaf frond $^{-1}$ ) reaching the maximum during the first week of October (161.0 nymph leaf ${ }^{-1}$ frond $^{-1}$ ) which subsequently dwindled to a minimum during April. The parasitisation by E. guadeloupae on RSW ranged from 31.60 per cent in Aug. 2018 to 57.60 per cent in December 2018. The association of biotic and abiotic factors with A. rugioperculatus population showed a negative correlation with E. guadeloupae and C. montrouzieri. There was a significant positive correlation between maximum temperature and minimum temperature as well as relative humidity. However, rainfall showed a negative correlation with $A$. rugioperculatus population.
\end{abstract}

Keywords: Abiotic factors, climate, exotic pest, population dynamics, whitefly

\section{Introduction}

Coconut (Cocos nucifera) is one of the most important crops in tropical areas. More than 900 species of pests are associated with coconut palm, which includes both invertebrates and vertebrates (Kumara et al., 2015). In India, rugose spiralling whitefly (RSW) an exotic pest was first reported by Shanas et al. (2016) from Kerala. In Tamil Nadu, the incidence of RSW, A. rugioperculatus (Hemiptera: Sternorrhyncha: Aleyrodidae) on coconut was first observed in Anaimalai block, Coimbatore during August 2016 (Srinivasan et al., 2016) and RSW had also been reported from Tamil Nadu, Karnataka, Kerala and Andhra Pradesh (Sundararaj and Selvaraj, 2017). RSW is a new exotic pest and also polyphagous which is likely to expand the host range as the species becomes more established. It mainly infests coconut palms and other broad-leaved hosts in its native range. The pest is somewhat superficially similar in its habit and general appearance to spiralling whitefly A. disperses, which itself is an invasive pest that came to India in the mid-1990s. RSW feeding causes stress to the host plant by removing water and nutrients and also by producing honeydew, which covers the lower leaves and results in the growth of sooty mould. Although sooty mould is not a plant disease, its presence on the upper surface of the leaf can potentially reduce photosynthesis of the plant (Shanas et al., 2016). Since the degree of incidence of spiralling whitefly changes with the season, it is desirable to have a thorough understanding of the

*Corresponding Author: elaento@gmail.com 
seasonal abundance of spiralling whitefly. Abiotic factors also play a key role in determining the incidence and dominance of a particular pest and their natural enemies in a crop ecosystem. However, natural enemies play a major role in bringing down the whitefly population in nature, and hence, an account of natural enemies is inevitable. With this objective, the seasonal incidence of spiralling whitefly and its natural enemies in relation to climatic factors were studied. The population buildup of any insect is very intimately related to the weather parameters (Boopathi et al., 2014). Influence of weather parameters on RSW incidence is lacking, which is essential for developing management strategies. Hence, the study also aimed at proposing a prediction of population fluctuation of RSW for devising management practices well in advance.

\section{Materials and methods}

\section{Population dynamics of coconut RSW, A. rugioperculatus}

\section{Seasonal incidence of $A$. rugioperculatus in coconut}

The population density of $A$. rugioperculatus on five-year-old coconut trees was assessed from 2017 to 2019. An earlier report by Elango et al. (2019) showed more damage with infestation index of 2.28 in Chowghat Orange Dwarf (COD) compared to other varieties. Ten coconut trees were selected randomly in the orchard of Horticultural College and Research Institute, TNAU, Coimbatore. The coconut trees maintained under pesticide-free environment were selected for observation of population dynamics of RSW, and the trees were supplied with proper macro and micronutrients and irrigation. The study was carried out for 21 months from October 2017 to April 2019, which coincided with $40^{\text {th }}$ standard meteorological week of 2017 to $17^{\text {th }}$ standard meteorological week of 2019. In each tree, the bottom matured five fronds were selected, and from each frond, five leaflets were marked for taking observations on population dynamics of RSW. Weekly observations were made in selected leaflets of the coconut tree, and the number of nymphs of $A$. rugioperculatus $1 \mathrm{eaf}^{-1}$ and the population of various natural enemies of RSW was also noted on these leaflets.

\section{Seasonal association of natural enemies}

Elango et al. (2019) recorded one species of aphelinid parasitoid and nine species of predators against this exotic pest, which are naturally available in RSW affected coconut gardens. Among all the natural enemies, one parasitoid from the Aphelinidae family, Encarsia guadeloupae and three predators viz., Mallada desjardinsi, Chrysoperla zastrowi sillemi and Cryptolaemus montrouzieri were found in more numbers, voraciously feeding on RSW and reducing the population. Natural parasitization of RSW by Encarsia guadeloupe and three predators was studied from October 2017 to April 2019 in coconut farm of Tamil Nadu Agricultural University, Coimbatore. The observations on the natural enemies of RSW were recorded at weekly intervals. The population of predators and parasitoids (dependent variable) recorded on RSW were correlated with weather factors (independent variable) viz., maximum temperature $\left(\mathrm{X}_{1}\right)$, minimum temperature $\left(\mathrm{X}_{2}\right)$, maximum relative humidity $\left(\mathrm{X}_{3}\right)$, minimum relative humidity $\left(\mathrm{X}_{4}\right)$ and total rainfall $\left(\mathrm{X}_{5}\right)$ obtained from Agro Climate Research Centre (ACRC), Coimbatore for the entire study period. The correlation analysis was done with two sets of experiments, (i) Current week population of biotic factors versus current week abiotic weather parameters and (ii) Current week population of biotic factors versus preceding week abiotic parameters to predict the favourable condition for RSW. Multiple regression analysis was also performed with both current and preceding week weather parameters.

\section{Statistical analysis}

\section{Studies on the seasonal population dynamics}

Simple correlation and multiple regression analyses were performed between dependent and independent variables using SPSS 16.0 statistical package to associate the incidence of A. rugioperculatus and their natural enemies with various biotic factors.

\section{Results and discussion}

It was found that the infestation was low during the rainy season, moderate during post rainy season and high in summer. RSW population was high 
Table 1. Correlation coefficient (r) among A. rugioperculatus population and its biotic (natural enemies) and abiotic factors (weather parameters)

\begin{tabular}{|c|c|c|c|c|c|c|c|c|c|c|}
\hline & $\mathbf{Y}$ & $\mathbf{X 1}$ & $\mathrm{X} 2$ & $\mathbf{X 3}$ & $\mathrm{X} 4$ & X5 & X6 & $\mathbf{X} 7$ & $\mathbf{X 8}$ & X9 \\
\hline $\mathrm{Y}$ & 1 & -.190 & $.491^{* *}$ & $.590^{* *}$ & $-.677^{* *}$ & $.299^{* *}$ & .101 & $.234^{*}$ & $.323^{* *}$ & -.081 \\
\hline $\mathrm{X} 1$ & & 1 & $-.228^{*}$ & -.210 & .123 & $-.460^{* *}$. & -.190 & -.147 & $-.227^{*}$ & .144 \\
\hline $\mathrm{X} 2$ & & & 1 & $.226^{*}$ & -.167 & $-.487^{* *}$ & $-.281^{*}$ & $.232^{*}$ & $.364^{* *}$ & .162 \\
\hline $\mathrm{X} 3$ & & & 1 & $-.334^{* *}$ & -.073 & .215 & .049 & $.277^{*}$ & .085 & \\
\hline $\mathrm{X} 4$ & & & & 1 & .113 & $-.218^{*}$ & -.117 & $-.383^{* *}$ & $-.341^{* *}$ & \\
\hline $\mathrm{X} 5$ & & & & & 1 & $.493^{* *}$ & $-.409^{* *}$ & $-.582^{* *}$ & -.152 & \\
\hline $\mathrm{X} 6$ & & & & & & 1 & $-.229^{*}$ & $.345^{* *}$ & .213 & \\
\hline $\mathrm{X} 7$ & & & & & & & 1 & $.292^{* * *}$ & .187 & \\
\hline X8 & & & & & & & & 1 & $.496^{* *}$ & \\
\hline X9 & & & & & & & & & 1 & \\
\hline
\end{tabular}

Y: A. rugioperculatus population leaf ${ }^{-1}$, X1: Per cent parasitism by Encarsia spp., X2: C. z.sillemi, X3: Mallada boninensis, X4: Cryptolaemus montrouzieri, X5: Maximum temperature $\left({ }^{\circ} \mathrm{C}\right), \mathrm{X} 6$ : Minimum temperature $\left({ }^{\circ} \mathrm{C}\right), \mathrm{X} 7$ : Maximum relative humidity (\%), X8: Minimum relative humidity (\%), X9: Rainfall (mm).

** Significant at $1 \%$, * Significant at 5\%, ns: non-significant, X1 to X4: Biotic factors, X5 to X9: Abiotic factors

Table 2. Multiple regression of $A$. rugioperculatus incidence at weekly interval with biotic and abiotic factors

\begin{tabular}{|c|c|c|c|c|c|c|c|c|c|}
\hline \multirow[t]{2}{*}{ Multiple regression } & \multicolumn{4}{|c|}{ Biotic factors } & \multicolumn{5}{|c|}{ Abiotic factors } \\
\hline & $\mathbf{X} 1$ & $\mathrm{X} 2$ & X3 & X4 & X5 & X6 & X7 & X8 & X9 \\
\hline Coefficients & 19.8967 & 8.1520 & 33.2709 & -2.3016 & -6.3139 & 1.3592 & 0.2139 & -1.2017 & -0.0748 \\
\hline Standard Error & 11.0621 & 2.1005 & 4.0533 & 0.1998 & 1.5285 & 1.6431 & 0.4557 & 0.3909 & 0.4381 \\
\hline T-value & $1.80^{\mathrm{NS}}$ & $3.88 * *$ & $8.21 * *$ & $-11.52 * *$ & $-4.13 * *$ & $0.83^{\mathrm{NS}}$ & $0.47^{\mathrm{NS}}$ & $-3.07 * *$ & $-0.17^{\mathrm{NS}}$ \\
\hline $\mathrm{R}^{2}$ & $0.85 * *$ & & & & & & & & \\
\hline F Value & $46.45 * *$ & & & & & & & & \\
\hline $\begin{array}{l}\text { Regression } \\
\text { equation } Y=401.37+\end{array}$ & $19.89(\mathrm{X} 1)+$ & $.15(\mathrm{X} 2)+3$ & 33.27 (X3) - & $2.30(X 4)-6$ & $6.31(\mathrm{X} 5)$ & $1.35(\mathrm{X} 6)$ & $-0.21(X 7$ & $-1.20(\mathrm{X} 8)$ & -0.07 (X9) \\
\hline
\end{tabular}

Y: A. rugioperculatus population leaf ${ }^{1}$, X1: Per cent parasitism by Encarsia spp., X2: C. z.sillemi, X3: Mallada boninensis X4: Cryptolaemus montrouzieri, X5: Maximum temperature $\left({ }^{\circ} \mathrm{C}\right), \mathrm{X} 6$ : Minimum temperature $\left({ }^{\circ} \mathrm{C}\right), \mathrm{X} 7$ : Maximum relative humidity (\%), X8: Minimum relative humidity (\%) X9: Rainfall (mm).

** Significant at $1 \%, *$ Significant at 5\%, ns: non-significant

during the first week of October 2018 (161 nymph leaf $^{-1}$ frond $\left.^{-1}\right)$ which coincided with $40^{\text {th }}$ standard meteorological week. A. rugioperculatus population was comparatively high from the first week of July 2018 (131 nymph leaf ${ }^{-1}$ frond $\left.^{-1}\right)$ till the last week of October 2018 (150 nymph leaf ${ }^{-1}$ frond $^{-1}$ ) which declined further up to March. Correlation between abiotic factors and A. rugioperculatus population revealed that maximum temperature $\left(\mathrm{r}=0.299^{*}\right)$ and minimum temperature $(\mathrm{r}=0.101)$ had significant positive correlations (Table 1 and 2). There was also a significant positive correlation between the minimum and maximum relative humidity $\left(\mathrm{r}=0.234^{*}\right)$ and $\left(\mathrm{r}=0.323^{* *}\right)$. However, rainfall $(\mathrm{r}=-0.181)$ showed a significant negative correlation with $A$. rugioperculatus population (Fig.1). The biotic and abiotic factors prevailing during the preceding week on the population of A. rugioperculatus showed significant association (Tables 3 and 4). The impact of E. guadeloupae population on the $A$. rugioperculatus population was negative and significant $(\mathrm{r}=-0.684 * *)$. Likewise, the population of $C$. montrouzieri was also negative and significant $(\mathrm{r}=-0.587 * *)$. The abiotic factors showed a significant correlation with A. rugioperculatus population in the case of 


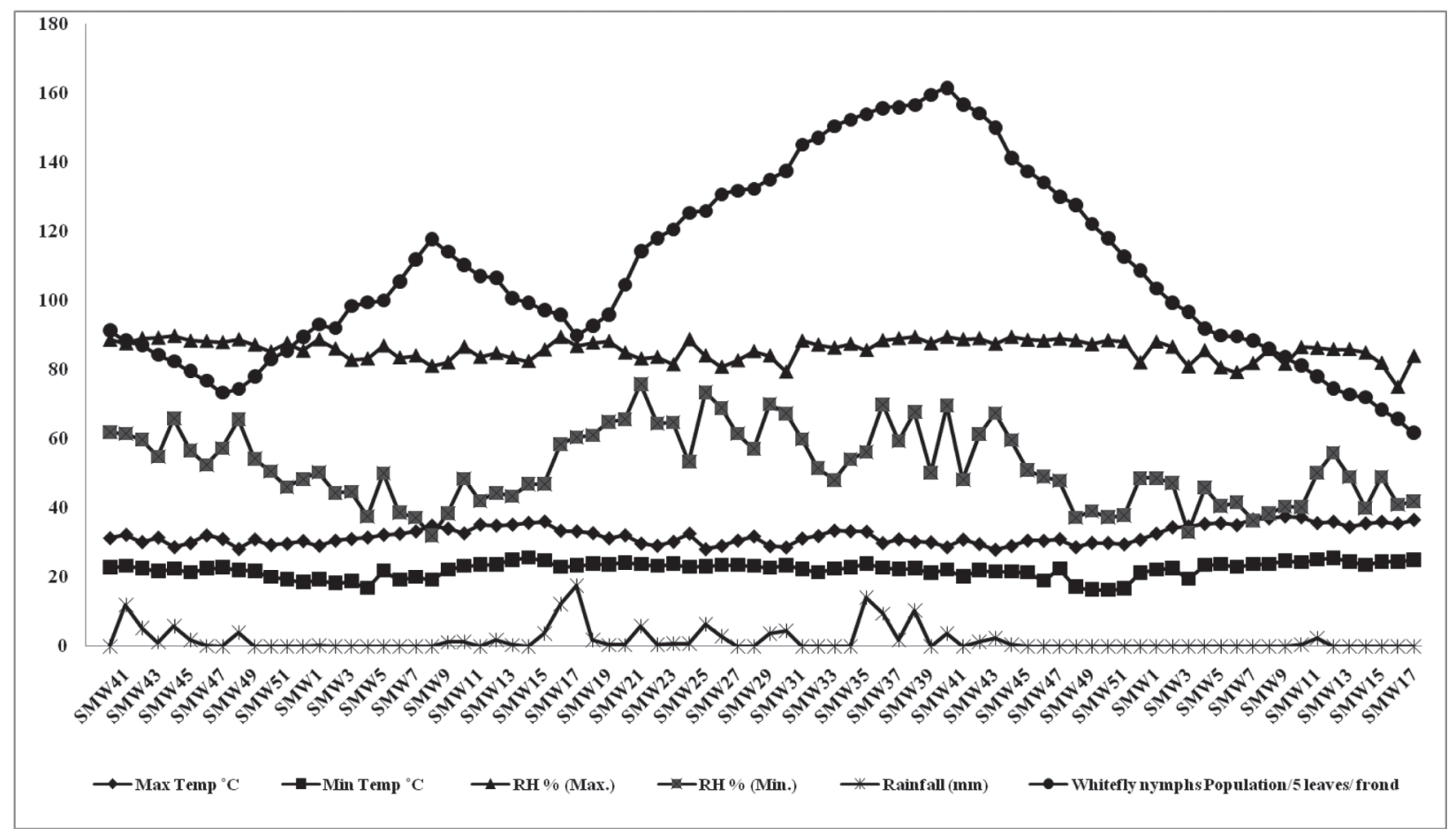

Fig 1. Seasonal incidence of A. rugioperculatus in coconut (October 2017 to April 2019)

maximum temperature $(\mathrm{r}=-0.462 * *)$ and evening relative humidity $(\mathrm{r}=0.352 * *)$. To study the combined effect, all the factors have been considered in multiple linear regression irrespective of their degree of contribution (Table 4). The multiple regression analyses showed the prediction of linear equation for $A$. rugioperculatus population (Y) as
$\mathrm{Y}=401.37+19.89(\mathrm{X} 1)+8.15(\mathrm{X} 2)+33.27(\mathrm{X} 3)$ $-2.30(X 4)-6.31(X 5)+1.35(X 6)+0.21(X 7)-1.20$ (X8) -0.07. All the biotic and abiotic factors jointly had a significant impact $\left(\mathrm{F}=46.45^{* *}\right)$ on A. rugioperculatus population. The coefficient of determination $\left(\mathrm{R}^{2}\right)$ was found to be 85 per cent. T-value had positive significant correlation with

Table 3. Correlation of $A$. rugioperculatus population with its biotic and abiotic factors of preceding week

\begin{tabular}{|c|c|c|c|c|c|c|c|c|c|c|}
\hline & $\mathbf{Y}$ & $\mathrm{X} 1$ & $\mathrm{X} 2$ & $\mathrm{X3}$ & $\mathrm{X} 4$ & X5 & $\mathrm{X6}$ & $\mathrm{X} 7$ & $\mathbf{X 8}$ & X9 \\
\hline $\mathrm{Y}$ & 1 & $-.684^{* *}$ & .180 & $.518^{* *}$ &.$-587^{* *}$ & $-0.462^{* *}$ & -.155 & .205 & $.352^{* *}$ & .145 \\
\hline $\mathrm{X} 1$ & & 1 & .153 & -.158 & $-.342^{* *}$ & .085 & -.198 & -.051 & $-.328^{* *}$ & $-.292^{* *}$ \\
\hline $\mathrm{X} 2$ & & & 1 & $-.318^{* *}$ & -.193 & $.298^{* *}$ & .019 & -.206 & $-.297^{* *}$ & -.094 \\
\hline $\mathrm{X} 3$ & & & & 1 & $.249^{*}$ & $-.474^{* *}$ & $-.243^{*}$ & .210 & $.375^{* *}$ & .203 \\
\hline $\mathrm{X} 4$ & & & & & 1 & -.081 & $.273^{*}$ & -.077 & $.332^{* *}$ & .106 \\
\hline $\mathrm{X} 5$ & & & & & & 1 & $.479^{* *}$ & $-.405^{* *}$ & $-.576^{* *}$ & -.145 \\
\hline X6 & & & & & & & 1 & $-.222^{*}$ & $.366^{* *}$ & $.224^{*}$ \\
\hline $\mathrm{X} 7$ & & & & & & & & 1 & $.287^{* *}$ & .184 \\
\hline X8 & & & & & & & & & 1 & $.493^{* *}$ \\
\hline X9 & & & & & & & & & & 1 \\
\hline
\end{tabular}

Y: A. rugioperculatus population leaf ${ }^{-1}$, X1: Per cent parasitism by Encarsia spp., X2: C. z.sillemi, X3: Mallada boninensis X4: Cryptolaemus montrouzieri, X5: Maximum temperature $\left({ }^{\circ} \mathrm{C}\right)$, X6: Minimum temperature $\left({ }^{\circ} \mathrm{C}\right)$, X7: Maximum relative humidity (\%), X8: Minimum relative humidity (\%), X9: Rainfall (mm).

** Significant at $1 \%, *$ Significant at 5\%, ns: non-significant, X1 to X4: Biotic factors, X5 to X9: Abiotic factors 
Table 4. Multiple regression of $A$. rugioperculatus population with biotic and abiotic factors of preceding week

\begin{tabular}{|c|c|c|c|c|c|c|c|c|c|}
\hline \multirow[t]{2}{*}{ Multiple regression } & \multicolumn{4}{|c|}{ Biotic factors } & \multicolumn{5}{|c|}{ Abiotic factors } \\
\hline & $\mathbf{X 1}$ & $\mathbf{X} 2$ & $\mathbf{X 3}$ & $\mathbf{X} 4$ & $\mathrm{X5}$ & X6 & $\mathrm{X} 7$ & X8 & X9 \\
\hline Coefficients & -2.266 & 33.644 & 10.409 & 32.887 & -6.138 & 1.877 & 1.002 & -1.129 & -.264 \\
\hline Standard Error & .183 & 11.286 & 2.034 & 3.936 & 1.435 & 1.546 & .435 & .366 & .410 \\
\hline T-Value & $-12.377 * * *$ & $2.981 * * *$ & $5.116 * * *$ & $8.355 * * *$ & $-4.277 * * *$ & $1.214^{\mathrm{NS}}$ & $2.304 * *$ & $-3.084 * * *$ & $-.643^{N S}$ \\
\hline $\mathrm{R}^{2}$ & $0.93 * *$ & & & & & & & & \\
\hline Fvalue & $53.52 * * *$ & & & & & & & & \\
\hline
\end{tabular}

Regression

equation $\mathrm{Y}=308.81-2.266(\mathrm{X} 1)+33.64(\mathrm{X} 2)+10.41(\mathrm{X} 3)+32.89(\mathrm{X} 4)-6.14(\mathrm{X} 5)+1.87(\mathrm{X} 6)+1.00(\mathrm{X} 7)-1.129(\mathrm{X} 8)-0.264(\mathrm{X} 9)$

Y: A. rugioperculatus population leaf ${ }^{-1}$, X1: Per cent parasitism by Encarsia spp., X2: C. z.sillemi, X3: Mallada boninensis, X4: Cryptolaemus montrouzieri, X5: Maximum temperature $\left({ }^{\circ} \mathrm{C}\right), \mathrm{X} 6$ : Minimum temperature $\left({ }^{\circ} \mathrm{C}\right), \mathrm{X} 7$ : Maximum relative humidity (\%), X8: Minimum relative humidity (\%), X9: Rainfall (mm).

** Significant at $1 \%$, Significant at $5 \%$, ns : non-significant

C. zastrowi sillemi $\left(\mathrm{T}=3.88^{*}\right)$ and $M$. boninensis $\left(\mathrm{T}=4.70^{* *}\right)$; while per cent parasitism by E. guadeloupae $(\mathrm{T}=1.80 \mathrm{NS}), C$. montrouzeiri $(\mathrm{T}=-11.52 * *)$, maximum temperature $\left(\mathrm{T}=-4.13^{* *}\right)$ and maximum relative humidity $(\mathrm{T}=-3.07 * *)$ had highly significant negative T-value.

Chandrika Mohan et al. (2017) reported that a shift in weather pattern reflected as deficit monsoon as one of the primary reasons for immediate upsurge of RSW. They are so sensitive to the wet season, heavy rains and also stated that an increase in temperature over $2^{\circ} \mathrm{C}$ during summer is another predisposing factor for the increase in the pest population. Deficit rainfall increased temperature, and reduced humidity was found to be the reasons for the flare-up and spread of the pest $A$. rugioperculatus (Josephrajkumar et al., 2018). Srinivasan et al. (2016) reported that prolonged dry spell is the main reason for proliferation and quick dispersal of the RSW in Tamil Nadu. According to Ranjith et al. (1996), A. dispersus increased drastically in summer and decreased after the premonsoon showers in Kerala. Narayanaswamy and Ramegowda (1999) found a high incidence of $A$. dispersus during April-June on mulberry. In Karnataka, the population of $A$. dispersus was found to be high during March-June (Mani and Krishamoorthy, 2000; Mallappanavar, 2000). Aishwariya et al. (2007) stated that white flies are present throughout the year in South India, with a high population in summer (March-June) and lower in winter (October-January). The nymphal population was low during June-July and reached a peak in November at Shimoga.

In the case of biotic factors, the parasitisation by E. guadeloupae ranged from 31.6 per cent (August 2018) to 57.6 per cent (December 2018). The population of C. zastrowi sillemi was very low in the coconut field throughout the study period. The occurrence of $C$. zastrowi sillemi in the field was observed from February 2018 to March 2018, and the population was very low ( 0.2 to 0.5 numbers leaf $\left.^{-1}\right)$. M. boninensis was more abundant during the first week of September 2018, which declined during the last week of August 2018 (2.90 grubs leaf $^{-1}$ frond $\left.^{-1}\right)$. C. montrouzieri population was high during the first week of August 2018 (1.2 grubs leaf $^{-1}$ frond $^{-1}$ ). The correlation coefficient of biotic factors with $A$. rugioperculatus population showed that all biotic factors had a negative correlation with A. rugioperculatus population. E. guadeloupae $(\mathrm{r}=-0.190)$ and $C$. montrouzeiri $(\mathrm{r}=-0.460 * *)$ had significant negative correlation with A. rugioperculatus population. The predators viz., Neuropterans and coccinellids also affected A. rugioperculatus as they were generalist and occur in very low numbers. This results conformed with Geetha (2000) who reported that the predators affected population dynamics of $A$. dispersus.

\section{Conclusion}

This study aimed to develop a prediction measures for the coconut RSW Aleurodicus rugioperculatus, using reliable and dependable 
weather variables that have a direct influence on the $A$. rugioperculatus incidence. It is concluded that maximum temperature and maximum RH was the reason for the RSW population flare-up. Rainfall showed a negative correlation with A. rugioperculatus population. The incidence of RSW was high from $28^{\text {th }}$ SMW to $44^{\text {th }}$ SMW of the year. It might be possible to predict RSW incidence in advance, which will help the farmers to assess the incidence and hike in the population of RSW for time management.

\section{Acknowledgement}

The authors are grateful to Dr. M. Ayyamperumal, Central Integrated Pest Management Centre, Directorate of Plant Protection Quarantine and Storage, Tiruchirappalli, Tamil Nadu, India for RSW parasitoids and predators identification respectively.

\section{References}

Aishwariya, K.K., Manjunatha, M. and Naik, M.I. 2007. Biology and host range of spiralling whitefly. Karnataka Journal of Agricultural Sciences 20(1): 149-152.

Boopathi, T., Singh, S.B., Manju, T., Dutta, S.K, Singh, A.R., Chowdhury, S., Ramakrishna, Y. and Dayal, V. 2017. Temporal modelling for forecasting of the incidence of litchi stink bug using ARIMAX analysis. Indian Journal of Horticulture 74(4): 604-607.

Chandrika Mohan, Josephrajkumar, A., Merin Babu, Prathibha, P.S., Krishnakumar, V., Hegde, V. and Chowdappa, P. 2017. Invasive Rugose Spiralling Whitefly on Coconut, Technical Bulletin No. 117, (Centenary Series 60), ICAR-CPCRI, Regional Station, Kayamkulam, 16 p.

Elango, K., Nelson, S.J., Sridharan, S., Paranidharan, V. and Balakrishnan, S. 2019. Biology, distribution and host range of new invasive pest of India, coconut rugose spiralling whitefly Aleurodicus rugioperculatus Martin in Tamil Nadu and the status of its natural enemies. International Journal of Agriculture Sciences 11(9): 8423-8426.

Geetha, B. 2000. Biology and management of spiralling whitefly, Aleurodicus dispersus (Russell) (Homoptera:
Aleyrodidae). Tamil Nadu Agricultural University; Coimbatore.

Josephrajkumar, A., Chandrika Mohan, P.S., Prathibha, T., Nalinakumari and Nair. C.P.R. 2018. Pest dynamics and suppression strategies. In: The Coconut Palm (Cocos nucifera L.)-Research and Development Perspectives . (Eds.) Nampoothiri, U., Krishnakumar, V., Thampan, P. K., Nair, M. A. Springer Nature Singapore Pte Ltd. pp. 557-634.

Kumara, A.D.N.T., Chandrashekharaiah, M., Kandakoor, S.B. and Chakravarthi, A.K. 2015. Status and management of three major insect pests of coconut in the tropics and subtropics. In: New Horizons in Insect Science: Towards Sustainable Pest Management pp. 359-381.

Mallappanavar, M.C. 2000. Bioecology and management of spiraling whitefly, Aleurodicus dispersus Russell by Verticillium lecanii (Zimm.) on guava. Doctoral dissertation, University of Agricultural Sciences, Dharwad, $76 \mathrm{p}$.

Mani, M. and Krishnamoorthy, A.A. 2000. Population dynamics of spiralling whitefly, Aleurodicus dispersus Russell (Aleyrodidae: Homoptera) and its natural enemies on guava in India. Entomon 25(1): 29-34.

Narayanaswamy, K.C. and Ramegowda, T. 1999. Incidence of spiralling whitefly on mulberry. Insect Environment 5: 128-129.

Ranjith, A.M., Rao, D.S. and Thomas, J. 1996. New host records of the mealy whitefly, Aleurodicus dispersus Russell in Kerala. Insect Environment 2(2): 35-38.

Shanas, S., Job, J., Joseph, T. and Anju Krishnan, G. 2016. First report of the invasive rugose spiraling whitefly, Aleurodicus rugioperculatus Martin (Hemiptera: Aleyrodidae) from the old world. Entomon 41: 365-368.

Srinivasan, T., Saravanan, P.A., Josephrajkumar, A., Rajamanickam, K., Sridharan, S., David, P.M.M., Natarajan, N. and Shoba, N. 2016. Invasion of the rugose spiraling whitefly, Aleurodicus rugioperculatus Martin (Hemiptera: Aleyrodidae) in Pollachi tract of Tamil Nadu, India. The Madras Agricultural Journal 103(10): 349-353.

Sundararaj, R. and Selvaraj. K. 2017. Invasion of rugose spiraling whitefly, Aleurodicus rugioperculatus Martin (Hemiptera: Aleyrodidae): A potential threat to coconut in India. Phytoparasitica 45(1): 71-4. 